\title{
Mathematical assessment of Canada's pandemic influenza preparedness plan
}

\author{
Abba B Gumel PhD ${ }^{1}$, Miriam Nuño PhD², Gerardo Chowell PhD ${ }^{3,4}$
}

\begin{abstract}
AB Gumel, M Nuño, G Chowell. Mathematical assessment of Canada's pandemic influenza preparedness plan. Can J Infect Dis Med Microbiol 2008;19(2):185-192.
\end{abstract}

OBJECTIVE: The presence of the highly pathogenic avian $\mathrm{H} 5 \mathrm{~N} 1$ virus in wild bird populations in several regions of the world, together with recurrent cases of $\mathrm{H} 5 \mathrm{~N} 1$ influenza arising primarily from direct contact with poultry, have highlighted the urgent need for preparedness and coordinated global strategies to effectively combat a potential influenza pandemic. The purpose of the present study was to evaluate the Canadian pandemic influenza preparedness plan.

PATIENTS AND METHODS: A mathematical model of the transmission dynamics of influenza was used to keep track of the population according to risk of infection (low or high) and infection status (susceptible, exposed or infectious). The model was parametrized using available Canadian demographic data. The model was then used to evaluate the key components outlined in the Canadian plan.

RESULTS: The results indicated that the number of cases, mortalities and hospitalizations estimated in the Canadian plan may have been underestimated; the use of antivirals, administered therapeutically, prophylactically or both, is the most effective single intervention followed by the use of a vaccine and basic public health measures; and the combined use of pharmaceutical interventions (antivirals and vaccine) can dramatically minimize the burden of the pending influenza pandemic in Canada. Based on increasing concerns of Oseltamivir resistance (wide-scale implementation), coupled with the expected unavailability of a suitable vaccine during the early stages of a pandemic, the present study evaluated the potential impact of nonpharmaceutical interventions (NPIs) which were not emphasized in the current Canadian plan. To this end, the findings suggest that the use of NPIs can drastically reduce the burden of a pandemic in Canada.

CONCLUSIONS: A deterministic model was designed and used to assess Canada's pandemic preparedness plan. The study showed that the estimates of pandemic influenza burden given in the Canada pandemic preparedness plan may be an underestimate, and that Canada needs to adopt NPIs to complement its preparedness plan.

Key Words: Antivirals; Control measures; Influenza; Pandemic; Preparedness plan; Vaccination

\section{Une évaluation mathématique du plan canadien de préparation à la pandémie d'influenza}

OBJECTIF : La présence du virus aviaire H5N1 hautement pathogène au sein de populations d'oiseaux sauvages de plusieurs régions du monde, combinée aux cas récurrents d'influenza H5N1 surtout causés par un contact direct avec de la volaille, soulignent l'urgence d'élaborer des stratégies de préparation mondiales et coordonnées pour lutter avec efficacité contre une pandémie d'influenza potentielle. La présente étude visait à évaluer le plan canadien de préparation à la pandémie d'influenza. PATIENTS ET MÉTHODOLOGIE : Les auteurs ont utilisé un modèle mathématique de la dynamique de transmission de l'influenza pour suivre la population d'après le risque d'infection (faible ou élevé) et le statut d'infection (susceptible, exposé ou infectieux). Ils ont établi les paramètres du modèle au moyen des données démographiques disponibles au Canada. Ils ont ensuite utilisé le modèle pour évaluer les principaux éléments exposés dans le plan canadien.

RÉSULTATS : D'après les résultats, le nombre de cas, de décès et d'hospitalisations évalué dans le plan canadien pourrait être sous-estimé. Le recours aux antiviraux, administrés pour des raisons thérapeutiques, prophylactiques ou les deux, est l'intervention unique la plus efficace, suivie par la vaccination et des mesures de santé publique de base. L'association d'interventions pharmaceutiques (antiviraux et vaccin) peut réduire considérablement le fardeau de la pandémie d'influenza escomptée au Canada. Étant donné l'inquiétude croissante quant à la résistance à l'oseltamivir (implantation généralisée) couplée à la non-disponibilité prévue d'un vaccin convenable pendant les premières phases d'une pandémie, la présente étude comprend une évaluation des répercussions potentielles d'interventions non thérapeutiques (INT) qui n'ont pas été mises de l'avant dans le plan canadien actuel. Ainsi, les observations laissent supposer que les INT pourraient aussi réduire considérablement le fardeau d'une pandémie au Canada.

CONCLUSION : Un modèle déterministe a été conçu et utilisé pour évaluer le plan canadien de préparation à la pandémie. L'étude a révélé que les évaluations du fardeau d'une pandémie d'influenza indiquées dans le plan de préparation à une pandémie d'influenza pourraient être sousestimées et que le Canada doit adopter des INT pour compléter ce plan de préparation.
$\mathrm{T}$ he main motivation of the present study stems from the encouragement we received from some government officials in Canada, to extend the earlier work on the analysis of the pandemic influenza preparedness plans to the United Kingdom (UK), the United States (US) and the Netherlands
(1), and to assess the Canadian pandemic influenza preparedness plan. Canada, like many other nations $(2,3)$, has formulated its pandemic preparedness plan in anticipation of a potential pandemic. The current version of the 609-page plan (published in 2006) entails the use of nonpharmaceutical interventions

${ }^{1}$ Department of Mathematics, University of Manitoba, Winnipeg, Manitoba; ${ }^{2}$ Department of Biostatistics, Harvard School of Public Health,

Boston, Massachusetts; ${ }^{3}$ Center for Nonlinear Studies, Mathematical Modeling and Analysis Group (MS B284), Los Alamos National

Laboratory, Los Alamos, New Mexico, ${ }^{4}$ School of Human Evolution and Social Change, Arizona State University, Tempe, Arizona, USA

Correspondence: Dr Abba B Gumel, Department of Mathematics, University of Manitoba, Winnipeg, Manitoba R3T 2N2.

Telephone 204-474-7486, fax 204-474-7602, e-mail gumelab@cc.umanitoba.ca

Received for publication April 25, 2007. Accepted September 4, 2007 


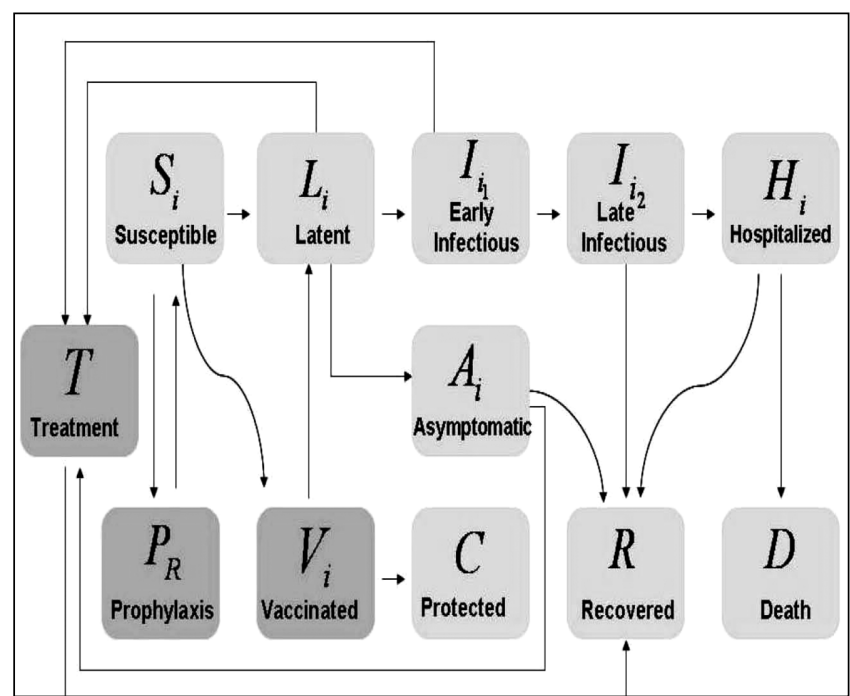

Figure 1) Flowchart diagram describing high-and low-risk populations considered in the proposed model (1), in which index i denotes high-risk and low-risk classes. Antiviral prophylaxis is only available to susceptibles while treatment may be given to latent, early-stage infectious and asymptomatic individuals. $\mathrm{C}$ and D classes account for the number of protected (via vaccination) and deceased cases, respectively

(NPIs) and pharmaceutical interventions (PIs) aimed at "curtailing serious illness and overall deaths, and minimizing societal disruption among Canadians as a result of an influenza pandemic" (4). Furthermore, the plan includes the use of effective surveillance systems, vaccination programs, antivirals and basic public health control measures aimed at reducing the risk of infection by discouraging public gatherings and school sessions. Similar to the plans proposed by the UK, the US and the Netherlands (5-7), Canada acknowledges the benefits of antivirals (both therapeutically and prophylactically) in reducing and slowing down the impact of a pandemic (particularly during the early stage of the pandemic, before a vaccine becomes available). Although Canadian public health officials recognize the importance of minimizing the impact of a potential pandemic via the use of the aforementioned interventions, a comprehensive quantitative assessment of the potential benefits of these interventions has not been carried out.

A number of mathematical modelling studies $(1,7-15)$, using stochastic as well as deterministic formulations, have been carried out to quantify the burden of a potential influenza pandemic and to assess various interventions. Most of these studies $(9,10,12-15)$ adopt large-scale stochastic simulation models to study nationwide spread of influenza. No doubt that these detailed modelling and simulation frameworks provide reasonable estimates and assessments of the potential impact of an influenza pandemic; however, the actual implementation of these models seem to rely on state-of-the-art computing resources and highly specific data, which are unlikely to be available in most countries (especially at the onset of a pandemic) (12).

In the present study, a deterministic compartmental model of the transmission dynamics of influenza was used to evaluate the potential impact of a pandemic in Canada under various control strategies. The model, which was used by the authors to evaluate the pandemic influenza preparedness plans for the Netherlands, the UK and the US (1), is simulated using demographic data from Canada. A schematic description of the
TABLE 1

Parameter and corresponding definitions used in the proposed model

\begin{tabular}{|c|c|}
\hline Parameter & Definition \\
\hline$\overline{R_{0}^{i}}$ & Basic reproduction number \\
\hline$\eta_{i}$ & Relative infectiousness of asymptomatic individuals \\
\hline$p$ & $\begin{array}{l}\text { Fraction of nontreated latent individuals who progress to } \\
\text { symptomatic class }\end{array}$ \\
\hline $1 / \phi_{i}$ & Latent period (days) \\
\hline$\psi i$ & Disease progression rate to late infectious class $\left(\right.$ days $\left.^{-1}\right)$ \\
\hline$\alpha_{i}$ & Hospitalization rate $\left(\right.$ days $\left.^{-1}\right)$ \\
\hline$\gamma_{l i}$ & Recovery rate for infectious individuals (days ${ }^{-1}$ ) \\
\hline$\gamma_{A i}$ & Recovery rate for asymptomatic individuals $\left(\right.$ days $^{-1}$ ) \\
\hline$\gamma_{H i}$ & Recovery rate for hospitalized individuals (days ${ }^{-1}$ ) \\
\hline $\mathrm{CFP}_{i}$ & Case fatality proportion for $i$-risk individuals \\
\hline$\delta_{i}$ & Mortality rate $\left(\right.$ days $\left.^{-1}\right), \delta \mathrm{i}=\left(\mathrm{CFP}_{i} / 1-\mathrm{CFP}_{i}\right) \times \gamma_{H i}$ \\
\hline$\pi_{i}$ & Community transmission reduction parameter \\
\hline$\zeta_{i}$ & Relative infectiousness of hospitalized individuals \\
\hline$q_{i}$ & Fraction of therapeutic antiviral recipients \\
\hline$a_{i}$ & $\begin{array}{l}\text { Fraction of latent individuals who are treated with antiviral } \\
\text { medication }\end{array}$ \\
\hline$\epsilon_{A i}$ & Antiviral efficacy \\
\hline$\sigma_{i}$ & Average protection rate via prophylaxis $\left(\right.$ days $\left.^{-1}\right)$ \\
\hline$\rho_{i}$ & Prophylactic antiviral rate $\left(\right.$ days $\left.^{-1}\right)$ \\
\hline$\phi_{i}$ & $\begin{array}{l}\text { Therapeutic antiviral rate for latent and asymptomatic } \\
\text { individuals }\left(\text { days }^{-1}\right)\end{array}$ \\
\hline$\xi_{i}$ & Therapeutic antiviral rate $\left(\right.$ days $\left.^{-1}\right)$ \\
\hline$\gamma_{T}$ & Recovery rate of treated individuals (days ${ }^{-1}$ ) \\
\hline$\epsilon_{V i}$ & Vaccine efficacy \\
\hline$v_{i}$ & Vaccination rate $\left(\right.$ days $\left.^{-1}\right)$ \\
\hline$K_{i}$ & Vaccine-induced protection rate $\left(\right.$ days $\left.^{-1}\right)$ \\
\hline
\end{tabular}

The index $i$ is used to denote the high-risk and low-risk classes. Particular values assumed are provided in reference 1

model is depicted in Figure 1; and the associated parameters are defined in Table 1. The present study provides a thorough assessment of the potential role of transmission control measures, antivirals and a vaccine to combat an influenza pandemic in Canada.

\section{PATIENTS AND METHODS}

The model (1) (Appendix, Figure 1) was used to evaluate various pandemic scenarios outlined in Canada's influenza preparedness plan (4). The model, which is deterministic in nature, subdivides the total Canadian population according to risk of infection (based on two main groupings, namely low risk or high risk) and current epidemiological states (eg, susceptible, exposed and infectious). For instance, the class of highrisk susceptible individuals is denoted by $S_{h}$, while that of low-risk susceptible individuals is represented by $S_{l}$. Although the epidemiological classes of the model are categorized according to a host's risk of infection, the model does not stratify the population according to ages (hence, it assumes that influenza spreads equally among age groups). The model is parametrized using Canadian-specific demographic data (Table 2), and is simulated under various scenarios to evaluate the Canadian plan. The first set of simulations carried out are associated with the baseline scenario (worst-case scenario), which represents the case in which no interventions have been 
TABLE 2

Initial conditions used for Canada and baseline estimates used in previous studies

\begin{tabular}{ll}
\hline Population size, $\mathrm{n}$ & $33,098,932^{*}$ \\
High risk, \% & 20 \\
Low risk, \% & 80 \\
Initial conditions & \\
$S_{h} ; S_{l}$ & $6,619,786 ; 26,479,146$ \\
$E_{i 1} ; E_{i 2}$ & $50 ; 50$ \\
$I_{i 1} ; I_{i 2}$ & $1 ; 1$ \\
Baseline predicted in the literature ${ }^{\dagger}$ & \\
$R_{0}$, range & $1.4-1.8$ \\
Case fatality, \% & 4 \\
Clinical attack rate, \% (range) & $15-35$ \\
Hospitalization rate, \% & 1 \\
\hline
\end{tabular}

*Statistics accessed at July 2006 from reference 26 ; ${ }^{\dagger}$ Data from reference 4

implemented. Further details about the formulation, analysis and simulations of the model can be obtained from Nuño et al (1).

The severity of an influenza pandemic can be quantified by its transmissibility as measured by the basic reproduction number. This quantity, denoted by $R_{0}$, represents the average number of secondary cases generated by an infectious individual during his or her infectious period, in a completely susceptible population. Severe outbreaks are associated with higher $R_{0}$ values, while mild outbreaks correspond to lower $R_{0}$ values. For instance, estimates for the basic reproduction number of the 1918/1919 influenza pandemic for several regions of the world ranged between 1.5 and 5.4 (16-21). This variability in estimates of $R_{0}$ can be attributed to the specific location and pandemic wave considered, as well as the spatial aggregation of the data and estimation method. As a comparison, the transmissibility of seasonal influenza epidemics (in which a fraction of the population is effectively protected from infection due to vaccination campaigns or cross-immunity) has been estimated to be approximately 1.3 with important year-to-year variability (22).

To compare the results of the present study with those projected in the Canadian plan (4), scenarios corresponding to mild, moderate and severe outbreaks were evaluated by considering a range of $R_{0}$ between 1.6 and 2.4. Table 3 provides the number of infections, hospitalizations and deaths that may be expected for the various ranges of $R_{0}$ simulated. The estimates indicate that incrementing $R_{0}$ from 1.6 to 2.4 increases the clinical attack rate from $30 \%$ to $51 \%$, while yielding a case fatality rate of $4 \%$ (1). It should be emphasized that the aforementioned ranges for $R_{0}$ are within the estimates discussed in the Canadian plan, and the clinical attack rates are comparable with those of other developed countries.

\section{RESULTS}

Several intervention scenarios were evaluated to study the impact of a potential influenza pandemic in Canada. NPIs were assessed in hospital settings and the general community based on transmission control measures that rely on the individual effort to increase hygiene, wear face masks and avoid social gatherings. PI strategies assume the implementation of antivirals and a prepandemic vaccine. Although it is not clear
TABLE 3

Baseline estimates (no intervention) for the cumulative number of infections, hospitalizations (HZ) and deaths for several basic reproduction numbers $\left(R_{0}\right)$ for Canada*

\begin{tabular}{cccccc}
\hline $\boldsymbol{R}_{\boldsymbol{0}}$ & $\begin{array}{c}\text { Infections } \\
\text { (million) }\end{array}$ & $\begin{array}{c}\mathrm{HZ} \\
\text { (million) }\end{array}$ & $\begin{array}{c}\text { Deaths } \\
\text { (n) }\end{array}$ & $\begin{array}{c}\text { Clinical } \\
\text { attack rate } \\
\mathbf{( \% )}\end{array}$ & $\begin{array}{c}\text { Case } \\
\text { fatality rate } \\
\text { (\%) }\end{array}$ \\
\hline 1.6 & 10 & 5.2 & 417,822 & 30 & 4 \\
1.9 & 14 & 7.0 & 559,612 & 42 & 4 \\
2.1 & 15 & 7.7 & 609,285 & 45 & 4 \\
2.4 & 17 & 8.5 & 670,276 & 51 & 4 \\
\hline
\end{tabular}

Clinical attack rate denotes the ratio of total infections and total population size, case fatality percentage denotes the ratio of deceased individuals and total infections. Baseline estimates provided by model in Section 2.1 in which $R_{0}=\max \left\{R_{0}^{h}, R_{0}^{l}\right\}$. *Proposed model used from reference 1

what the effectiveness (if any) of a nonpandemic strain vaccine would be, it is assumed that readily available vaccine resources may be used to alleviate symptoms and combat infection. The combination of these interventions (NPIs and PIs) will also be assessed.

\section{NPIs: Basic control measures}

The impact of basic transmission control measures only in the community or hospitals alone were studied, and these interventions were evaluated in both settings. As stated in the Canadian influenza pandemic preparedness plan, communitybased interventions may include reduction in the transmission rate of disease through increased hygiene, face masks and closing places of public gatherings and schools. First, it is assumed that these basic transmission control measures are implemented partially and, thus, vary reduction levels in the transmission rate (risk of infection). In particular, if these basic control measures are only implemented in hospitals, and not in communities (ie, $\pi_{i}=1$ and $\zeta_{i} \neq 1$ ) and the efficacy of the hospital intervention is assumed to vary between $10 \%\left(\zeta_{i}=0.9\right)$ and $90 \%\left(\zeta_{i}=0.1\right)$, the number of deaths, hospitalizations and infections can be reduced (from the baseline) significantly by $73 \%$ (from 559,612 to 120,992 ), $79 \%$ (from seven million to 1.5 million) and $77 \%$ (from 14 million to 3.2 million), respectively (Table 4, top panel). Similarly, the potential impact of reducing control measures in the community setting alone can be assessed $\left(\pi_{i} \in[0.1,1]\right.$ and $\left.\zeta_{i}=1\right)$. This scenario gives even better outcome than the previous one (Table 4, panel 2). The results of an outbreak assuming a baseline were compared with a strategy that implemented 20\% control measures in the community for various ranges of $R_{0}$ (Figure 2 ). It can be observed that for mild influenza pandemics $\left(R_{0}=1.6\right), 20 \%$ communitybased transmission reduction control measures suffice to contain the rate of infection below what is typically observed during seasonal influenza outbreaks. However, as $R_{0}$ exceeds 1.9, these level of interventions are no longer sufficient to maintain disease at low levels.

The combined use of the two basic control measures is also explored. For instance, assuming the implementation of a $20 \%$ effective basic control measure in the community, while allowing hospital control measures to vary between $0 \%$ and $90 \%$ (or assuming $20 \%$ control measures in the hospital while varying community measures between $0 \%$ and $90 \%$ ) reduces deaths, hospitalizations and infections dramatically (Table 4, third and fourth panels). Furthermore, to assess some of the expected 
TABLE 4

Baseline estimates $\left(R_{0}=1.9\right)$ for the final cumulative deaths, hospitalizations and total cases for various scenarios of control measures in hospital and community settings

\begin{tabular}{|c|c|c|c|c|c|}
\hline$\pi_{i}$ & $\zeta_{i}$ & $\begin{array}{c}\text { Reduction } \\
\text { factors (\%) } \\
1-\pi_{i}, 1-\zeta_{i}\end{array}$ & $\begin{array}{c}\text { Deaths } \\
\text { (n) }\end{array}$ & $\begin{array}{l}\text { Hospitalizations } \\
\text { (n) }\end{array}$ & $\begin{array}{l}\text { Infections } \\
\text { (n) }\end{array}$ \\
\hline 1.0 & 0.1 & 0,90 & 120,992 & $1.5 \mathrm{M}$ & $3.2 \mathrm{M}$ \\
\hline 1.0 & 0.4 & 0,60 & 359,821 & $4.5 \mathrm{M}$ & $9 \mathrm{M}$ \\
\hline 1.0 & 0.7 & 0,30 & 482,754 & $6.1 \mathrm{M}$ & $12.2 \mathrm{M}$ \\
\hline 1.0 & 0.9 & 0,10 & 540,429 & $6.8 \mathrm{M}$ & $13.6 \mathrm{M}$ \\
\hline 1.0 & 1.0 & 0,0 & 559,612 & $7 \mathrm{M}$ & $14 \mathrm{M}$ \\
\hline 0.1 & 1.0 & 90,0 & 12 & 149 & 295 \\
\hline 0.4 & 1.0 & 60,0 & 7,710 & 103,515 & 216,916 \\
\hline 0.7 & 1.0 & 30,0 & 430,123 & $5.4 \mathrm{M}$ & $11 \mathrm{M}$ \\
\hline 0.9 & 1.0 & 10,0 & 529,758 & $6.7 \mathrm{M}$ & $13.4 \mathrm{M}$ \\
\hline 1.0 & 1.0 & 0,0 & $559,612 \mathrm{M}$ & $7 \mathrm{M}$ & $14 \mathrm{M}$ \\
\hline 0.8 & 0.1 & 20,90 & 29 & 353 & 701 \\
\hline 0.8 & 0.4 & 20,60 & 52,896 & 700,759 & $1.5 \mathrm{M}$ \\
\hline 0.8 & 0.7 & 20,30 & 360,857 & $4.5 \mathrm{M}$ & $9.1 \mathrm{M}$ \\
\hline 0.8 & 0.9 & 20,10 & 448,548 & $5.7 \mathrm{M}$ & $11.3 \mathrm{M}$ \\
\hline 0.8 & 1.0 & 20,0 & 477,073 & $6 \mathrm{M}$ & $12 \mathrm{M}$ \\
\hline 0.1 & 0.8 & 90,20 & 8 & 89 & 175 \\
\hline 0.4 & 0.8 & 60,20 & 81 & 1012 & 2029 \\
\hline 0.7 & 0.8 & 30,20 & 337,388 & $4.2 \mathrm{M}$ & $8.5 \mathrm{M}$ \\
\hline 0.9 & 0.8 & 10,20 & 460,164 & $6 \mathrm{M}$ & $12 \mathrm{M}$ \\
\hline 1.0 & 0.8 & 0,20 & 508,852 & $6.4 \mathrm{M}$ & $13 \mathrm{M}$ \\
\hline
\end{tabular}

Parameters $1-\pi_{i}$ and $1-\zeta_{i}$ denote efficacy of transmission control measures in communities and hospitals, respectively. M Million

uncertainties associated with the use of basic control measures (it is prudent to expect that any estimates for efficacy of these measures, for instance, may involve a certain degree of uncertainty), the impact of these measures is also studied by assuming a fixed reduction factor for either community or hospital settings while sampling 100 simulation values of the other (nonfixed) control measure. The mean number of deaths, hospitalizations and infections are then calculated under this scenario. The results, tabulated in Table 5, illustrate that basic control measures are more effective when introduced in the general community rather than in hospitals.

The impact of these measures is illustrated graphically in Figure 3, in which it is shown that a program based on the use of hospital control measures alone (and no reduction in community transmission, $\pi_{i}=1$ ), requires a $100 \%$ reduction in hospital transmission to significantly reduce morbidity and mortality (left upper panel). Furthermore, a $70 \%\left(1-\pi_{i} \approx 0.3\right)$ reduction in community control measures reduces morbidity and mortality significantly (right upper panel). However, using a fixed $20 \%$ reduction in community transmission $\left(\pi_{i}=0.8\right)$ or hospital transmission $\left(\zeta_{i}=0.8\right)$ reduces the required threshold of hospital and community control measures from $100 \%$ to $75 \%$ and from $70 \%$ to $50 \%$, respectively (bottom panel).

Because the impact of basic control measures (4) was fully modelled, the role of these interventions was studied for several pandemic scenarios (corresponding to $R_{0}=1.6,1.9,2.1$ and 2.4). Figure 4 shows that reductions in hospital control
A

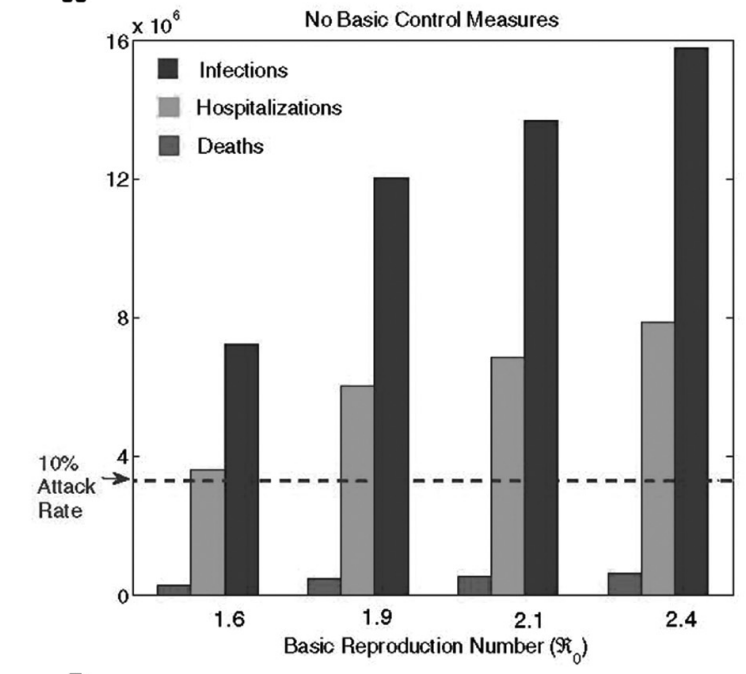

B

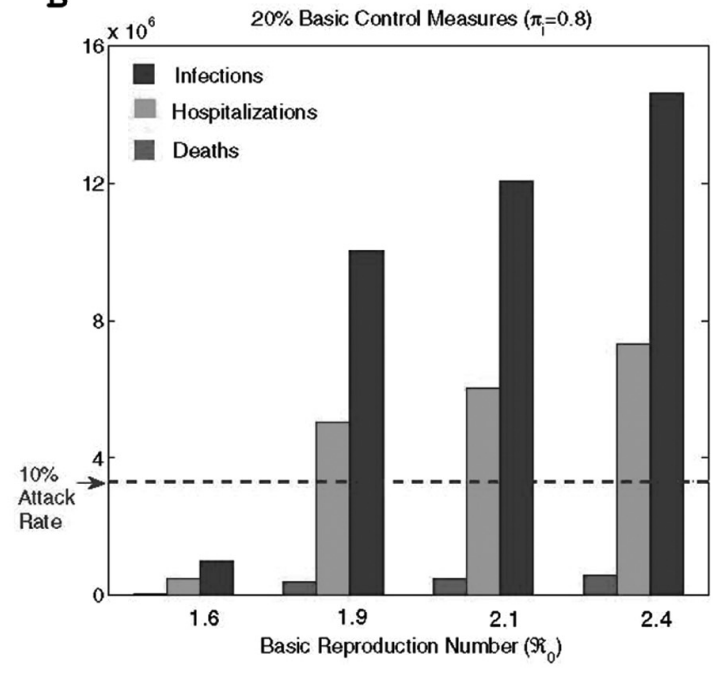

Figure 2) Baseline scenarios illustrating the final number of infections, hospitalizations and deaths for various basic reproduction numbers assuming (A) no basic control measures and (B) 20\% basic control measures in the community. The dashed line emphasizes the clinical attack rate for a typical (seasonal) influenza outbreak (10\% clinical attack rate)

measures necessary to significantly reduce morbidity and mortality depends strongly on $R_{0}$. For instance, as $R_{0}$ increases from 1.6 to 1.9 , hospital control measures necessary to effectively curtail the pandemic-related morbidity and mortality increases from $30 \%$ to $75 \%$. However, if $R_{0}$ increases to 2.4 , hospital control measures alone are shown to ineffectively combat an influenza pandemic in Canada (Figure 4, rightbottom panel). A detailed summary of the impact of control measures for an $R_{0}$ baseline of 1.9 is depicted in Table 4 .

\section{PIs}

In this section, it is assumed that two main PIs, namely antivirals and a vaccine, are used. Antivirals may be implemented therapeutically, prophylactically or in combination; and a vaccination program is implemented either alone or in combination with antivirals. While considering the impact of single PIs, it is assumed that antivirals may be administered therapeutically and prophylactically. The impact of the uncertainty 
TABLE 5

Mean results of 100 simulations generated by uniformly sampling the antiviral and vaccine efficacy from appropriate ranges as assumed in each scenario. Baseline scenario assumes $R_{0}=1.9$

\begin{tabular}{|c|c|c|c|c|c|c|}
\hline Single interventions & $\begin{array}{c}D_{\text {mean }} \\
(n)\end{array}$ & $\begin{array}{c}\mathrm{H}_{\text {mean }} \\
\text { (n) }\end{array}$ & $\begin{array}{c}I_{\text {mean }} \\
\text { (n) }\end{array}$ & $\begin{array}{c}T_{\text {mean }} \\
(n)\end{array}$ & $\begin{array}{c}P_{\text {mean }} \\
(n)\end{array}$ & $\begin{array}{c}\mathrm{C}_{\text {mean }} \\
\text { (n) }\end{array}$ \\
\hline \multicolumn{7}{|l|}{ Control measures only* } \\
\hline Community measures only & 17,304 & 230,029 & 477,670 & NA & NA & NA \\
\hline Combined measures ( $20 \%$ hospital reduction fixed) & 146 & 1889 & 3863 & NA & NA & NA \\
\hline Combined measures ( $20 \%$ community reduction fixed) & 35,497 & 458,885 & 940,200 & NA & NA & NA \\
\hline \multicolumn{7}{|l|}{$\mathrm{lb}$} \\
\hline Treatment and prophylaxis: sampled $\epsilon_{A h} \in(0.3 ; 0.5)$ & 15 & 196 & 430 & 141 & $9.4 \times 10^{8}$ & NA \\
\hline Treatment and prophylaxis: sampled $\in_{A l} \in(0.5 ; 0.7)$ & 14 & 169 & 371 & 126 & $10 \times 10^{8}$ & NA \\
\hline Treatment only: sampled $\epsilon_{A h} \in(0.3 ; 0.5)$ & 405,598 & $5.3 \mathrm{M}$ & $12 \mathrm{M}$ & $3.8 \mathrm{M}$ & NA & NA \\
\hline Treatment only: sampled $\epsilon_{A l} \in(0.5 ; 0.7)$ & 408,765 & $5.2 \mathrm{M}$ & $12 \mathrm{M}$ & $4 \mathrm{M}$ & NA & NA \\
\hline Prophylaxis only: sampled $\epsilon_{A h} \in(0.3 ; 0.5)$ & 74 & 954 & 1907 & NA & $9.2 \times 10^{8}$ & NA \\
\hline Treatment and prophylaxis: sampled $\epsilon_{A l} \in(0.5 ; 0.7)$ & 3 & 32 & 122 & 112 & $10 \times 10^{8}$ & NA \\
\hline Treatment only: sampled $\epsilon_{A h} \in(0.3 ; 0.5)$ & 12 & 147 & 617 & 580 & NA & NA \\
\hline Treatment only: sampled $\epsilon_{A l} \in(0.5 ; 0.7)$ & 46 & 600 & 2266 & 1902 & NA & NA \\
\hline Prophylaxis only: sampled $\epsilon_{A h} \in(0.3 ; 0.5)$ & 19 & 236 & 468 & NA & $11 \times 10^{8}$ & NA \\
\hline Prophylaxis only: sampled $\epsilon_{A l} \in(0.5 ; 0.7)$ & 24 & 305 & 606 & NA & $11 \times 10^{8}$ & NA \\
\hline \multicolumn{7}{|l|}{ Vaccine only $\ddagger$} \\
\hline \multicolumn{7}{|l|}{ lb } \\
\hline Sampled $\epsilon_{V I} \in(0.5 ; 0.7)$ & 9 & 90 & 177 & NA & NA & $33 \mathrm{M}$ \\
\hline Sampled $\in_{V h} \in(0.3 ; 0.5)$ & 10 & 105 & 206 & NA & NA & $33 \mathrm{M}$ \\
\hline \multicolumn{7}{|l|}{ ub } \\
\hline
\end{tabular}

The mean number of deceased $\left(D_{\text {mean }}\right)$, hospitalized $\left(H_{\text {mean }}\right)$, infections $\left(I_{\text {mean }}\right)$, antiviral treatment $\left(T_{\text {mean }}\right)$, antiviral prophylaxis $\left(P_{\text {mean }}\right)$ and vaccinated $\left(C_{\text {mean }}\right)$ individuals. The antiviral-only scenario considers lower-bound (lb) and upper-bound (ub) parameters (presented in reference 2) for treatment and prophylaxis, treatment-only and prophylaxis antivirals-only, respectively. ${ }^{*}$ Mean of 100 simulations sampled from $\left(\zeta_{j} \pi_{i}\right) \in(0.1,0.5) ;{ }^{\dagger}$ Mean of 100 simulations sampled from $\epsilon_{A h} \in$ $(0.3 ; 0.5)$ and $\epsilon_{A l} \in(0.5 ; 0.7)$; ${ }^{ \pm}$Mean of 100 simulations sampled from $\epsilon_{V h} \in(0.3 ; 0.5)$ and/or $\epsilon_{V I} \in(0.7 ; 0.9)$. M Million, NA Not applicable

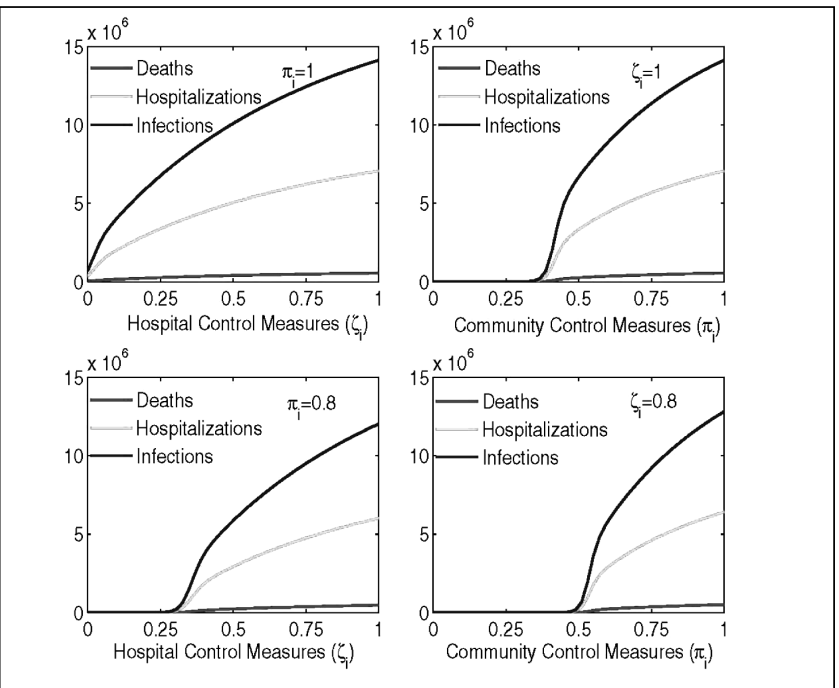

Figure 3) The final number of deaths, hospitalizations and infections for varying reduction factors in hospital $\left(1-\zeta_{\mathrm{i}}\right)$ and community settings $\left(1-\pi_{\mathrm{i}}\right)$. Top panels assume single control measures in either hospitals $\left(\pi_{\mathrm{i}}=1\right.$ : left upper panel) or in community $\left(\zeta_{\mathrm{i}}=1\right.$ : right upper panel) while bottom panels assume control measures in both of these settings. $\mathrm{R}_{0}=1.9$ is assumed

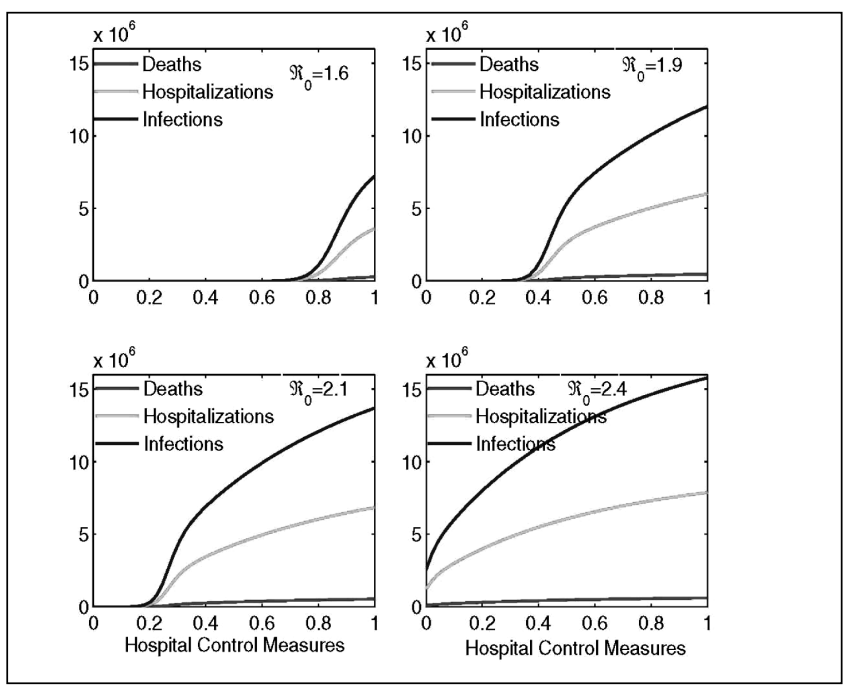

Figure 4) Baseline scenarios illustrating the final number of deaths, hospitalizations and infections for varying levels of hospital control measures. A fixed $20 \%\left(\pi_{i}=0.9\right)$ reduction in community control measures was assumed and hospital control measures were varied from $0 \%$ to $100 \%\left(\zeta_{\mathrm{i}}\right)$ for $\mathrm{R}_{0}=1.6,1.9,2.1,2.4$ 


\begin{tabular}{|c|c|c|c|c|c|c|}
\hline Combined Interventions & $\mathrm{D}_{\text {mean }}$ & $\mathrm{H}_{\text {mean }}$ & $I_{\text {mean }}$ & $\mathrm{T}_{\text {mean }}$ & $P_{\text {mean }}$ & $\mathrm{C}_{\text {mean }}$ \\
\hline \multicolumn{7}{|l|}{ Antiviral vaccine ${ }^{*}$} \\
\hline $\begin{array}{l}\text { Ib: Antivirals and vaccine: } \\
\text { sampled } \epsilon_{V I} \in(0.7 ; 0.9)\end{array}$ & 6 & 60 & 130 & 46 & $7.6 \mathrm{M}$ & $33 \mathrm{M}$ \\
\hline $\begin{array}{l}\text { Ib: Antivirals and vaccine: } \\
\text { sampled } \epsilon_{V h} \in(0.3 ; 0.5)\end{array}$ & 6 & 67 & 146 & 50 & $7.6 \mathrm{M}$ & $33 \mathrm{M}$ \\
\hline $\begin{array}{l}\text { ub: Antivirals and vaccine: } \\
\text { sampled } \in_{V I} \in(0.7 ; 0.9)\end{array}$ & 2 & 22 & 80 & 76 & $10 \mathrm{M}$ & $33 \mathrm{M}$ \\
\hline $\begin{array}{l}\text { ub: Antivirals and vaccine: } \\
\text { sampled } \epsilon_{V h} \in(0.3 ; 0.5)\end{array}$ & 2 & 22 & 76 & 74 & $10 \mathrm{M}$ & $33 \mathrm{M}$ \\
\hline \multicolumn{7}{|l|}{ Control measures and antivirals ${ }^{\dagger}$} \\
\hline Ib: Sampled $\epsilon_{A h} \in(0.3 ; 0.5)$ & 7 & 87 & 188 & 78 & $9 \times 10^{8}$ & NA \\
\hline ub: Sampled $\in_{A h} \in(0.3 ; 0.5)$ & 3 & 31 & 102 & 88 & $10 \times 10^{8}$ & NA \\
\hline \multicolumn{7}{|c|}{ Control measures, antivirals and vaccine ${ }^{\ddagger}$} \\
\hline Ib: Sampled $\epsilon_{V h} \in(0.3 ; 0.5)$ & 5 & 53 & 115 & 40 & $7.6 \mathrm{M}$ & $33 \mathrm{M}$ \\
\hline ub: Sampled $\in_{V h} \in(0.3 ; 0.5)$ & 2 & 20 & 70 & 68 & $10 \mathrm{M}$ & $33 \mathrm{M}$ \\
\hline
\end{tabular}

The mean number of deceased $\left(D_{\text {mean }}\right)$, hospitalized $\left(H_{\text {mean }}\right)$, infections $\left(I_{\text {men }}\right)$, antiviral treatment $\left(T_{\text {mean }}\right)$, antiviral prophylaxis $\left(P_{m e a n}\right)$ and vaccinated $\left(C_{\text {mean }}\right)$ individuals. *Mean of 100 simulations sampled from $\in_{V I} \in(0.7$; 0.9) and $\epsilon_{V h} \in(0.3 ; 0.5)$; ${ }^{\dagger}$ Mean of 100 simulations sampled from $\in_{A h} \in(0.3$; 0.5); $¥$ Mean of 100 simulations sampled from $\in_{V h} \in(0.3 ; 0.5)$. $M$ million; $N A$ Not applicable; ub upper-bound; Ib lower-bound parameters presented in reference 1

involved in the use of PIs (measured primarily in terms of the uncertainty in antiviral efficacy and coverage rates) is investigated. Simulations assume several scenarios that can be considered as 'optimistic' and 'less optimistic'. In the former scenario, high-coverage and efficacy levels are assumed while in the latter, these levels are low. First, the scenario in which antivirals are implemented both therapeutically and/or prophylactically for the lower-bound (lb) and the upper-bound (ub) parameters for various ranges of antiviral efficacy $\left(\in A_{h}\right.$, $\left.\in A_{l}\right)$ is considered. Assuming antiviral efficacy variability between $30 \%$ and $50 \%(\in A \in[0.3,0.5])$ for high-risk individuals results in 15 deaths, 196 hospitalizations and 430 infections (average values shown in Table 5). However, using the optimistic parameter values (ub), these estimates reduce to three deaths, 29 hospitalizations and 115 infections. Then the scenario in which antivirals are implemented therapeutically only $\left(\rho_{i}=\sigma_{i}=0\right)$ for both the $\mathrm{lb}$ and $\mathrm{ub}$ parameters is considered. Here, the optimistic scenario gives an estimate of 12 deaths, 147 hospitalizations and 617 infections. It is worth noting that in the less optimistic scenario, these estimates are significantly higher. Considering the scenario in which antivirals are implemented prophylactically only $\left(q_{i}=a_{i}=\theta_{i}=0\right)$, it is shown that high coverage rates and antiviral efficacy estimates the average number of deaths to 19 , hospitalizations 236 and 468 infections, compared with the less optimistic estimates (74 deaths, 954 hospitalizations and 1907 infections) (Table 5).

Although Canada anticipates that a pandemic-specific influenza vaccine will not be available during the first wave of the pandemic, the potential role of an antipandemic vaccine is explored by assuming that a 'partially suitable' vaccine is available at the onset of the pandemic. Our results for the four scenarios that allow for variability in vaccine efficacy for both high- $\left(\in \mathrm{V}_{h} \in[0.3,0.5]\right)$ and low-risk $\left(\in \mathrm{V}_{l} \in[0.7,0.9]\right)$ individuals show seven to nine deaths, 69 to 105 hospitalizations, and 133 to 206 infections. Last, several scenarios are explored that involve combined interventions (Table 6). Because the current preparedness plan for Canada involves the combined use of the aforementioned PIs, the impact of the combined use of antivirals and a vaccine is also assessed. Several scenarios were also evaluated allowing for variability in vaccine $\left(\in V_{i}\right)$ and antivirals $\left(\in A_{i}\right)$ efficacy for both high- and low-risk individuals. The results show a mean of two to six deaths, 22 to 67 hospitalizations, and 76 to 146 infections (Table 6).

In summary, the present study results for single interventions suggest that the use of antivirals, both therapeutically and prophylactically, is the most effective single strategy for combating an influenza pandemic in Canada (this is in conformity to the results by Nuño et al [1] and Ferguson et al [10]). This is followed by the use of a vaccine. Although our results for the singular use of basic control measures (in hospitals and communities) are not as effective as the use of antivirals or a vaccine, the reduction in morbidity and mortality provided by the former is notably significant. Thus, it is prudent to also consider intervention plans that incorporate basic control measures in Canada's plan (especially in light of the expected delay in vaccine availability during the early stages of the pandemic and the potential risk of resistance development in persons taking antivirals).

\section{DISCUSSION}

Canada's pandemic influenza preparedness plan includes an assessment of health and economic impact of a prospective pandemic (23). The Canadian plan reports estimates of clinical attack rates that range from $15 \%$ to $35 \%$. For these rates, the average number of influenza cases obtained were 4,545,177 and $10,605,415$, respectively. These estimates included the average number of deaths, hospitalizations and infections for the corresponding clinical attack rate. Compared with our model, the Canadian plan estimates did not account for the basic transmission control measures, antivirals and the vaccine.

We carried out both baseline scenarios, and scenarios that involved the evaluation of the potential impact of PIs and NPIs. Furthermore, our study stratified the Canadian population according to epidemiological states and specified riskspecific subpopulations. The results obtained from our study suggest that the burden of an influenza pandemic in Canada may be larger than the 10,284,2265 cases of morbidity and mortality (assuming a 35\% attack rate and a demographic data of 1999) discussed in the Canada preparedness plan (4). Although it is not clear what is the estimate of $R_{0}$ that is associated to the above estimate of the final epidemic size (as reported in the Canadian plan), our simulations yield an estimate of 15,617,822 (Table 2), assuming an $R_{0}$ value of 1.6 (the smallest in the range of simulations). Our findings suggest that the Canadian plan may be underestimating the potential burden of an influenza pandemic. However, if control measures are incorporated in our model, the estimate obtained $\left(11,190,773\right.$, Table 5 for $\pi_{i}=1$ and $\left.\zeta_{i} \in[0.1,0.5]\right)$ compares reasonably well with that reported in the Canadian plan.

Although the assumption of the availability of a partiallysuitable vaccine at the onset of a pandemic is clearly not a realistic one, our study assumes that a nonpandemic-specific 
vaccine may be available and could be used to provide partial protection. Canada's current plan of action involves mass vaccination implemented on a continuous prioritized basis (eg, health care workers and high-risk individuals) and soon after the pandemic strain-specific vaccine becomes available. However, the availability of a fully effective vaccine is likely to be available long (approximately six to nine months) after the onset of the first observed cases. The present study suggests that the use of a partially effective vaccine, combined with the potential benefits of a readily available pneumococcal vaccine (which forms part of the preparedness plans of the UK and the Netherlands) could prevent influenza-related complications and help curtail the burden of an influenza pandemic in Canada.

Finally, our study suggests that the use of antivirals is the most effective means of reducing morbidity and mortality associated with pandemic influenza in Canada. However, the relatively recent mutations of the avian influenza virus in humans in Egypt, to a form that might be resistant to the antiviral medications (24), suggest some caution in the use of this intervention (25). Considering this concern (danger of antiviral resistance) and the expected shortage of a suitable vaccine during the early stages of an influenza pandemic, it seems prudent to emphasize and develop methods to further evaluate NPIs in the Canadian plan.

ACKNOWLEDGEMENTS: Miriam Nuño was partially funded by the Yerby Postdoctoral Fellowship and National Institutes of Health grants T32AI07358 and R01EB006195. Dr Gerardo Chowell was supported through a Director's Postdoctoral Fellowship from Los Alamos National Laboratory. Dr Abba B Gumel acknowledges the support, in part, of the Natural Science and Engineering Research Council and Mathematics of Information Technology and Complex Systems of Canada, as well as the Canadian Institute for Health Research. The authors are grateful to the anonymous reviewers for their useful comments.

\section{REFERENCES}

1. Nuño M, Chowell G, Gumel AB. Assessing the role of basic control measures, antivirals and vaccine in curtailing pandemic influenza: Scenarios for the US, UK and the Netherlands. JR Soc Interface 2007;4:505-21.

2. Usher-Pines L, Omer SB, Barnett DJ, Burke TA, Balicer RD. Priority setting for pandemic influenza: An analysis of national preparedness plans. PLoS Med 2006;3:e436.

3. Flu Wiki. List of national pandemic influenza plans. <http://www.fluwikie.com/pmwiki.php?n=Geographic. CountryPlanList $>$ (Version current at October 30, 2007).

4. Public Health Agency of Canada. The Canadian pandemic influenza plan for the health sector. <http:/www.phac-aspc.gc.ca/ cpip-pclcpi/pdf-e/CPIP-2006_e.pdf > (Version current at October 30, 2007).

5. Department of Health. Pandemic flu. <http://www.dh.gov.uk/ PolicyAndGuidance/EmergencyPlanning/PandemicFlu/fs/en $>$ (Version current at October 30, 2007).

6. National Strategy for pandemic Influenza Implementation Plan: Homeland Security Councial, May 2006.

<http://www.whitehouse.gov/homeland/nspi_implementation.pdf> (Version current at October 30, 2007).

7. van Genugten ML, Heijnen ML, Jager JC. Scenario analysis of the expected number of hospitalisations and deaths due to pandemic influenza in the Netherlands.

<http://www.who.int/csr/disease/influenza/netherlands2.pdf> (Version current at October 30, 2007).

8. Eischner M, Schwehm M, Duerr HP, Brockmann SO. The influenza pandemic preparedness tool InfluSim. BMC Infec Dis 2007;7:17.

\section{Mathematical model}

\section{APPENDIX}

The total population is denoted by $N(t)$ and consists of a number of mutually exclusive subpopulations according to their epidemiological state: susceptible $\left(S_{i}\right)$, latent $\left(L_{i}\right)$, earlystage infectious $I_{i 1}$, late-stage infectious $I_{i 2}$, asymptomatic and partially infectious $\left(A_{i}\right)$, hospitalized $\left(H_{i}\right)$, therapeutic $(T)$ and prophylactic $\left(P_{i}\right)$ antiviral recipients, successfully vaccinated (but not yet protected) $\left(\mathrm{V}_{i}\right)$, protected via vaccination $(\mathrm{C})$, recovered $(R)$ and disease-induced dead $(D)$ individuals, in which the index $i$ is used to denote the high-risk $(h)$ and lowrisk $(l)$ individuals. The model consists of the following system of differential equations (where a dot represents differentiation with respect to time).

$$
\begin{aligned}
& \dot{S}_{i}=\sigma_{i} P_{i}-\left(\epsilon_{A i} \rho_{i}+v_{i}+\lambda_{i}\right) S_{i} \\
& \dot{L}_{i}=\lambda_{i} S_{i}+\lambda_{V i} V_{i}-\left(a_{i} \epsilon_{A i} \theta_{i}+\left(1-a_{i}\right) \phi_{i}\right) L_{i} \\
& \dot{A}_{i}=\left(1-a_{i}\right)(1-\rho) \phi_{i} L_{i}-\left(\epsilon_{A i} \phi_{i}+\gamma_{A i}\right) A_{i} \\
& \dot{l}_{i 1}=\left(1-a_{i}\right) \rho \phi_{i} L_{i}-\left[\epsilon_{A i} \xi_{i} q_{i}+\left(1-q_{i}\right) V_{i}+\left(1-\epsilon_{A i}\right) q_{i} V_{i}\right] I_{i 1} \\
& \dot{l}_{i 2}=\left[\left(1-\epsilon_{A i}\right) q_{i} V_{i}+\left(1-q_{i}\right) V_{i}\right] l_{i 1}-\left(\gamma_{l i}+\alpha_{i}\right) l_{i 2} \\
& \dot{H}_{i}=\alpha_{i} l_{i 2}-\left(\gamma_{H i}+\delta_{i}\right) H_{i} \\
& \dot{P}_{i}=\epsilon_{A i} \rho_{i} S_{i}-\left(\sigma_{i}+\epsilon_{V i} v_{i}\right) P_{i} \\
& \dot{T}=\epsilon_{A i} \sum_{i=h, l}\left(a_{i} \phi_{i} L_{i}+q_{i} \xi_{i} I_{i 1}+\theta_{i} A_{i}\right)-\gamma_{T} T \\
& \dot{V} i=\epsilon_{V i} V_{i} P_{i}+v_{i} S_{i}-\left(\lambda_{V i}+K_{i}\right) V_{i} \\
& \dot{R}=\sum_{i=h, l}\left(\gamma_{A i} A_{i}+\gamma_{l i} I_{i 2}+\gamma_{H i} H_{i}\right)+\gamma_{T} T \\
& \dot{C}=\sum_{i=h, l} K_{i} V_{i} \\
& \dot{D}=\sum_{i=h, l} \delta_{i} H_{i}
\end{aligned}
$$

9. Ferguson NM, Cummings DA, Cauchemez S, et al. Strategies for containing an emerging influenza pandemic in Southeast Asia. Nature 2005;437:209-14.

10. Ferguson NM, Cummings DA, Fraser C, Cajka JC, Cooley PC, Burke DS. Strategies for mitigating an influenza pandemic. Nature 2006;442:448-52.

11. Gani R, Hughes H, Fleming D, Griffin T, Medlock J, Leach S. Potential impact of antiviral drug use during influenza pandemic. Emerg Infect Dis 2005;11:1355-62.

12. Germann TC, Kadau K, Longini IM, Macken CA. Mitigation strategies for pandemic influenza in the United States. Proc Natl Acad Sci USA 2006;103:5935-40.

13. Longini IM Jr, Halloran ME, Nizam A, Yang Y. Containing pandemic influenza with antiviral agents. Am J Epidemiol 2004;159:623-33.

14. Longini IM Jr, Nizam A, Xu S, et al. Containing pandemic influenza at the source. Science 2005;309:1083-7.

15. Longini IM, Halloran ME. Strategy for distribution of influenza vaccine to high-risk groups and children. Am J Epidemiol 2005;161:303-6.

16. Chowell G, Nishiura H, Bettencourt LM. Comparative estimation of the reproduction number for pandemic influenza from daily case notification data. J Roy Soc Interface 2007;4:155-66.

17. Mills CE, Robins JM, Lipsitch M. Transmissibility of 1918 pandemic influenza. Nature 2004:432:904-6.

18. Viboud C, Tam T, Fleming D, Handel A, Miller MA, Simonsen L. Transmissibility and mortality impact of epidemic and pandemic influenza, with emphasis on the unusually deadly 1951 epidemic. Vaccine 2006;24:6701-7. 
19. Andreasen V, Viboud C, Simonsen L. Epidemiologic characterization of the summer wave of the 1918 influenza pandemic in Copenhagen: Implications for pandemic control strategies. J Infect Dis 2008;197:270-8.

20. Nishiura $\mathrm{H}$. Time variations in the transmissibility of pandemic influenza in Prussia, Germany, from 1918-19. Theor Biol Med Model 2007:4-20.

21. Chowell G, Ammon CE, Hengartner NW, Hyman JM. Estimation of the reproductive number of the Spanish flu epidemic in Geneva, Switzerland. Vaccine 2006;24:6747-50.

22. Chowell G, Miller MA, Viboud C. Seasonal influenza in the United States, France, and Australia: Transmission and prospects for control. Epidemiol Infect 2007;1-13.
23. Meltzer MI, Cox NJ, Fukuda K. The economic impact of pandemic influenza in the United States: Priorities for intervention. Emerg Infec Dis 1999;5:659-71.

24. Bird flu mutations in Egypt suggest antiviral resistance. $<$ http://www.usatoday.com/news/health/ 2007-01-18-bird-flu-mutations_x.htm > (Version current at October 30, 2007).

25. Lipsitch M, Cohen T, Murray M, Levin BR. Antiviral resistance and the control of pandemic influenza. PLoS Med 2007; 4:e15.

26. The world factbook <http://www.cia.gov/cia/publications/ factbook/index.html> (Version current at October 30, 2007). 


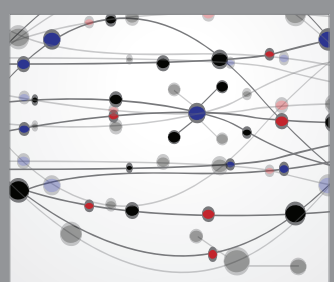

The Scientific World Journal
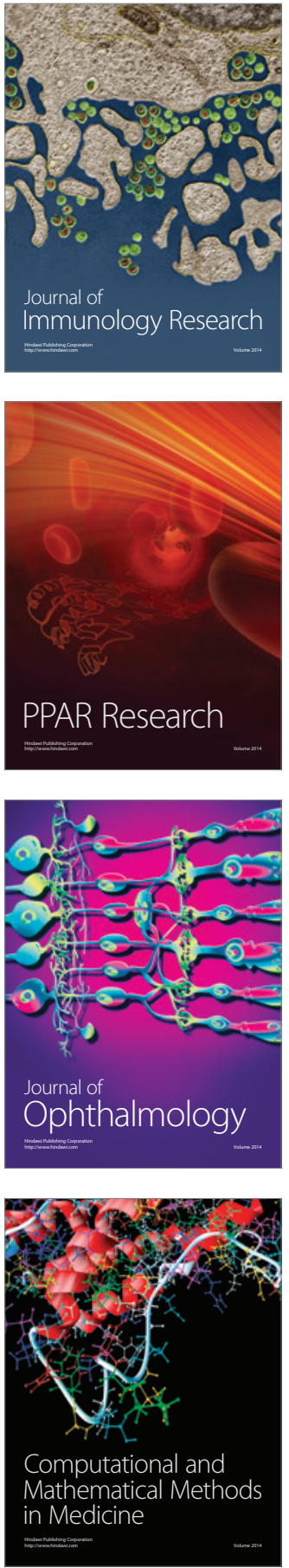

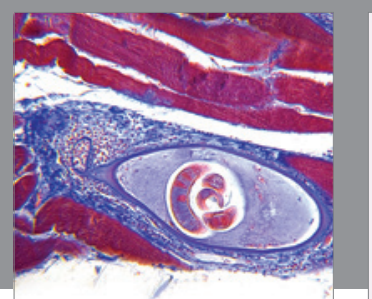

Gastroenterology Research and Practice

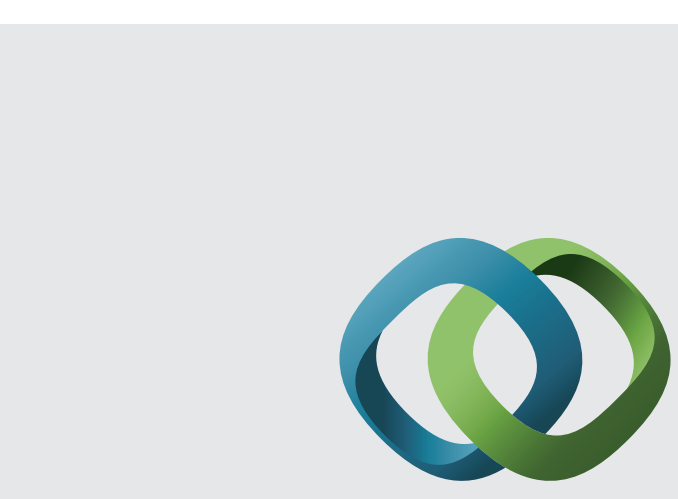

\section{Hindawi}

Submit your manuscripts at

http://www.hindawi.com
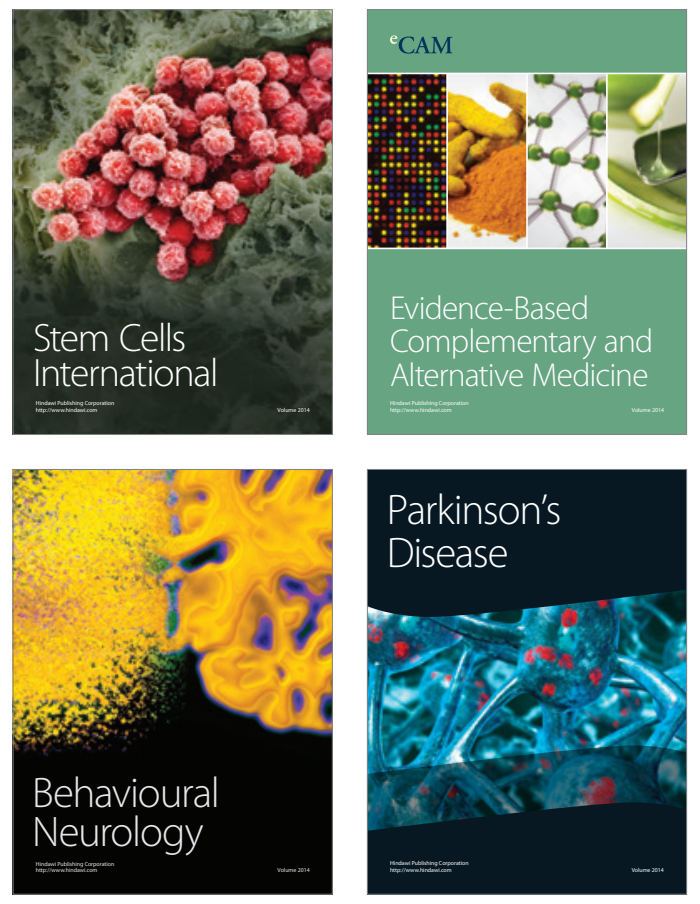
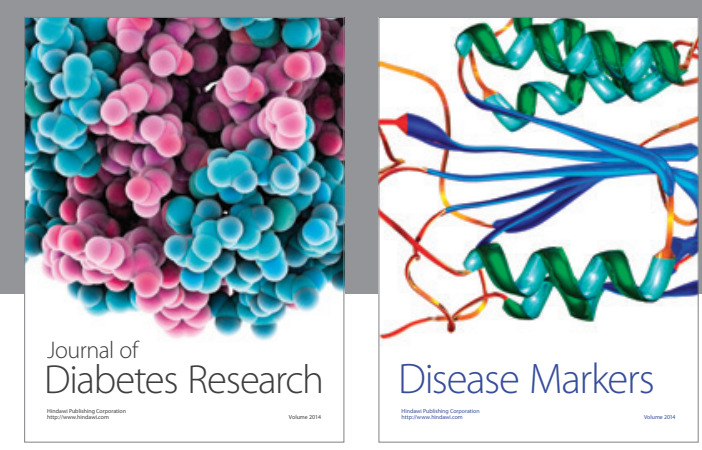

Disease Markers
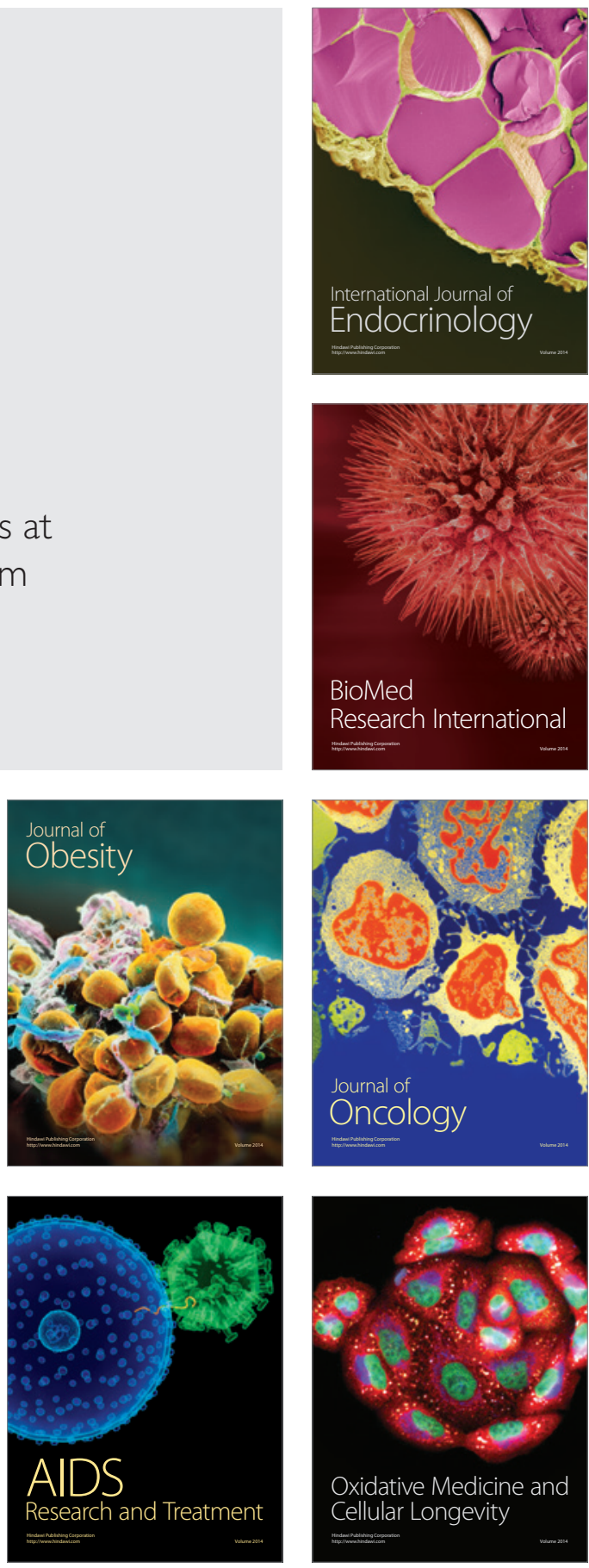